\title{
INCREASING THE EQUITY OF A FLOWER SUPPLY CHAIN BY IMPROVING ORDER MANAGEMENT AND SUPPLIER SELECTION
}

\author{
Moreno, J. R. ; Mula, J.* \& Campuzano-Bolarin, F.** \\ ${ }^{*}$ CIGIP (Research Centre on Production Management and Engineering), \\ Universitat Politècnica de València, Plaza Ferrándiz y Carbonell, 2, 03801, Alcoy, Alicante, Spain \\ ${ }^{* *}$ Business Management Department, Universidad Politécnica de Cartagena, \\ Campus Muralla del Mar, s/n, 30202, Cartagena, Murcia, Spain \\ E-Mail: cero084@hotmail.com,fmula@cigip.upv.es, francisco.campuzano@upct.es
}

\begin{abstract}
This work focuses on helping the decision-making process of a microenterprise, the central organisation of a flower-exporting supply chain, to satisfy the objective of increasing its equity value by $300 \%$, and that of the whole supply chain at the same time. A systems dynamics-based simulation model is developed to evaluate the order management process in the supply chain under study, its financial evaluation and a supplier selection module from the central firm. The objective is to increase the equity value of the central firm and the supply chain under study. The main contribution of this work is to model and simulate a real world supply chain for decision-making. Hence, this paper can be used by other supply chains as a reference for modelling and simulating themselves in order to improve their performance.

(Received in February 2014, accepted in November 2014. This paper was with the authors 4 months for 2 revisions.)
\end{abstract}

Key Words: Order Management, Financial Management, Supplier Selection, Systems Dynamics, Simulation

\section{INTRODUCTION}

In Cooper et al. [1], a new conceptualisation of supply chain management is proposed where business processes determine a cut-off in the tasks performed by participating firms, while each firm has its own set of tasks that must be related to each key process. Integrating key processes helps meet the supply chain's objectives. For this reason, the managers who form part of the chain must make strategic decisions for all the participating entities. Nonetheless, these decisions can be quite complex given the large quantity of visible and invisible relations between tangible and intangible factors, and they may also entail risk, which must be assumed because it is not absolutely certain what results can be attained in the future. Since it is necessary to know what will happen in the future to make better decisions in the present, different methods are available that help decision making. One of them is supply chain simulation.

Supply chain simulation entails modelling a system that represents all or part of its structure, which means abstracting its factors more simply by representing the operation of the part to be simulated. According to Campuzano and Mula [2], there are several reasons for supply chain simulation, which include: observations from real systems can prove impossible or costly; the complexity of representing a supply chain by mathematical equations and, despite representing them by such equations being impossible, obtaining a solution with analytical techniques may prove complex; it helps identify most of the relevant variables and the interaction among them; it helps consider different scenarios whose information is unknown; it helps evaluate new policies or decision rules before running a risk in a real supply chain. However, we may wish to simulate different objectives in distinct areas or chain 
subsystems, and by different analysis types, depending on the problem that the chain is faced with. In Calderon and Lario [3], 70 articles on the simulation of supply chains are reviewed and the main concepts are identified.

In Terzi and Cavalieri [4], four different simulation methods are distinguished in the supply chain context: simulation using spreadsheets, a user-friendy well-proven method to analyse multi-level supply chain management techniques by simulating different scenarios [5], systems dynamics, systems dynamics simulation with discrete events and business games. In order to conduct this work, the systems dynamics simulation model was used. Jay Forrester founded the so-called industrial dynamics method which later became known as systems dynamics [6]. According to Forrester [7], industrial dynamics is the study of the feedback characteristics of information to show how the organisation structure, amplification (in policies) and backlog times interact to influence whether the firm's objectives are met or not. Systems dynamics constructs a model that helps establish the relations between the elements making up the system structure, and analyses the relation among these elements and the system's final performance.

This work focuses on helping the decision-making process in a microenterprise, which is the central organisation of a flower-exporting supply chain, based on changes made in the policies or investments considered to satisfy the contemplated objective of increasing its equity value. To this end, a model is developed to work with the supply chain's order management and its financial evaluation, as is a module for the central firm's supplier selection. Simulation is run by systems dynamics. Based on this simulation, potential scenarios are analysed to see how each one influences the change in factors and, therefore, the objective that the chain considers. The remainder of the article is arranged as follows: Section 2 reviews the state of the art in order management simulation, supplier selection and financial evaluation. Section 3 describes the supply chain to be modelled, except for all its members and the order management process in the supply chain. Section 4 defines the supply chain simulation objective and the scenarios considered to meet this objective. It also explains the supply chain simulation model by means of causal and flow diagrams of all the sections identified for its simulation. Section 5 evaluates the simulation results, while Section 6 offers the conclusions drawn and future research lines.

\section{LITERATURE REVIEW}

Using the concepts that they applied to model order management in supply chains, Alarcon et al. [8] establish a conceptual framework to model collaborative order management by integrating the key aspects that must be considered. Abid et al. [9] present a mathematical model to maximise customer satisfaction in terms of delivery dates by optimising serving orders with the lead times available for delivery on time. Jung et al. [10] propose a mathematical model that represents the negotiation model between a distributor and its supplier to determine the amounts to be supplied when the product price is set by the market in a supply chain controlled by the distributor. Khataie et al. [11] develop a mixed integer multi-objective programming model that considers profit in order to make effective decisions on accepting orders in the supply chain. Khataie et al. [12] introduce a new approach which integrates the $\mathrm{ABC} / \mathrm{M}$ (activity-based costing and management) technique with the systems dynamics simulation methodology for order management problems. Kirche et al. [13] develop an order management model to integrate profitability capacity and analysis, and they compare the efficacy of activity-based costing (ABC) and theory of constraints (TOC) to evaluate the profitability of an order. Kirche and Srivastava [14] introduce the ABC concepts with mixed integer programming by describing the physical flow and process characteristics for orders management and the profitability analysis in a firm faced with demands that exceed capacity. 
Wang et al. [15] analyse the orders dispatching problem and consider a mathematical model designed by neuronal networks as an orders manager to help orders management in production distribution. Dordevic et al. [16] use both simulation and analytic hierarchy processes (AHP), and multiple attribute decisions, to optimise managers decisions on the information and material flow within multilevel part regeneration systems.

In the supplier selection simulation context, Amin et al. [17] apply SWOT (strengths, weaknesses, opportunities and threats) quantification for the first time as a decision tool to devise strategic supplier selection plans by integrating fuzzy logic and triangular fuzzy numbers to overcome inaccuracies of human thought. Ding et al. [18] contemplate a new methodology, which is basically composed of three modules: an optimiser using a genetic algorithm for supplier selection; a discrete events simulator to evaluate operational performance; a supply chain modelling framework. Lin [19] suggests a method that involves two stages: the first combines an analytical network process (ANP) with fuzzy preference programming (FPP) to create a more powerful fuzzy ANP tool for supplier selection by identifying the interdependency effects among the different selection criteria, and optimum order allocation for each selected supplier; the second stage provides optimum order allocation for all the selected suppliers. Mafakheri et al. [20] propose a two-stage systems dynamics multiple criteria programming approach: the first uses AHP to address the multiple criteria decision in the suppliers ranking; in the second stage, the suppliers ranking is introduced into the orders allocation model to maximise the utility function and to minimise the total cost. Zouggari and Benyoucef [21] adopt a new two-phase decision-making approach. In the first phase, suppliers are selected using a fuzzy AHP in four criteria classes. In the second, price criteria, quality and delivery are quantitatively evaluated to allocate orders to suppliers by means of the fuzzy simulation-based TOPSIS (technique for order performance by similarity to ideal solutions) technique.

For financial evaluation simulation, Comelli et al. [22] propose implementing the $\mathrm{ABC}$ approach, management costs and payment terms with a view to estimating the cash flow created by the planning that evaluates tactical production planning. Smith and MartinezFlores [23] compare traditional formulations and the present net value of finite horizons in economic order quantity (EOQ) in discrete times. Guillen et al. [24] contemplate the integration of supply chain planning/programming into the chemical sector with multi-level and multi-product distribution networks and financial management. Guillen et al. [25] present a holistic optimisation approach by combining operating and financial aspects in a supply chain. In the present work, the work of Guillen et al. [24] is taken as a reference framework to model the financial evaluation. Gurning et al. [26] assess potential mitigation strategies (inventory and sourcing mitigation, contingency rerouting, recovery planning and business continuity planning) through a Markovian-based methodology.

\section{DESCRIPTION OF THE SUPPLY CHAIN}

The central axis of the complete chain is a firm that commercialises flowers. There are two supplier types: a group of crop suppliers that provide the product according to variety and a cardboard factory that supplies the firm commercialising flowers with boxes to pack the product in. A transport company also forms part of the chain, which is in charge of consolidating and managing loads, and of issuing the corresponding documents. There is also a customs agency in charge of issuing the documents that have to be presented to customs. Indirectly, there is an airline by which the product is sent to the customer's destination (see Fig. 4). Neither the loading firm nor the customs agency was taken into account in this work as the transport company is not affected by any change in the interactions it has with the firm that commercialises flowers, and because flow with the customs agency is of the information 
type and the documents it prepares do not represent major variations in supply chain operations. Hence for the simulation consisting in representing the order management process, only the suppliers (cardboard factory and 13 crop suppliers), the firm that commercialises flowers and customers were considered (see Fig. 1).

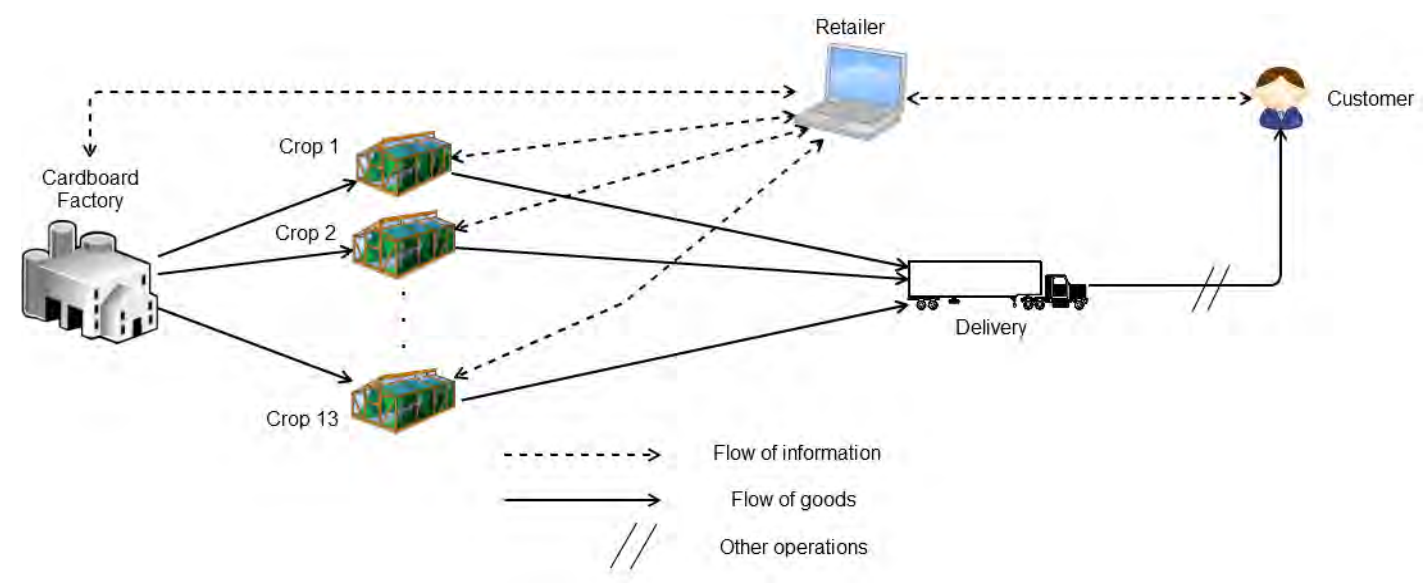

Figure 1: The SC structure to be simulated.

The firm commercialising flowers, referred to henceforth as FDLR, is a microenterprise that sells and manages the international distribution of flowers from various crops. In order to manage demand, a search is done and contact is made with customers. Attaining new customers is done personally by offering the firm's products and services. Two order types are managed with both new and current customers: fixed orders, when a customer is committed to buy $X$ amount weekly with discount prices; non-fixed orders, which are sporadic in nature. After orders arrive, the firm must contact the crop suppliers to verify product availability for a given date. If the order is large, it is necessary to contact several crop suppliers. FDLR must also contact the cardboard factory that supplies the boxes to pack flowers. When an order has been accepted, the product order is sent to the crop supplier(s), the order of boxes reaches the cardboard factory before the dispatching process is performed, and qualified staff is subcontracted to check quality. After inspections, boxes are closed and loaded onto refrigerated trucks. FDLR neither manages the inventory nor comes into physical contact with the product, other than inspecting its quality.

The cardboard factory provides boxes to pack the product. Since this firm supplies boxes to most crop suppliers, they send their own trucks to pick up the packing material they order, and FDLR makes full use of this transport by informing the cardboard factory which crop suppliers it must deliver boxes to. Likewise, the crop supplier is informed that it must pick up packing material at the cardboard factory. In $50 \%$ of orders, a truck needs contracting to pick up boxes and to take them to the airport, where it must hand them over to the truck drivers of other crop suppliers so they can deliver them to the respective crop supplier. This cardboard factory has the capacity to supply FDLR with 180 boxes a day.

Presently, there are 13 crop suppliers. They can ensure a number of products depending on their production capacity. So occasionally, FDLR must order products from different crop suppliers to serve the same order. Each crop supplier has a price, a payment deadline, a quality and different inventory availability. In addition, these suppliers are grouped according to the type of flower grown. The data corresponding to each crop supplier are specified in Table I.

FDLR agrees on the order with the crop supplier(s) by taking into account customer requirements. So as the crop supplier counts on the packing material and products required, it must pack the product and send it to the airport loading terminal to deliver orders to the transport company. Before delivery, a quality inspection needs to be done, which is the only 
time that FDLR comes into physical contact with the product sent by a third subcontracted party for inspection purposes. One of the suppliers is located in another city and it is among the suppliers that supply more quantity. However, the product is sent directly to the transport company to be consolidated with the rest of the order. This means that one part of the product leaves with the crop already packed from the other city without being submitted to quality inspection.

Table I: Suppliers data table.

\begin{tabular}{|l|c|c|c|c|c|}
\hline \multirow{3}{*}{ Type of flower } & $\begin{array}{c}\text { Number of } \\
\text { supplier }\end{array}$ & $\begin{array}{c}\text { Available } \\
\text { flowers }\end{array}$ & $\begin{array}{c}\text { Unit } \\
\text { price }(\$)\end{array}$ & $\begin{array}{c}\text { Payment } \\
\text { deadline (days) }\end{array}$ & $\begin{array}{c}\text { Quality } \\
(0-1)\end{array}$ \\
\hline \multirow{4}{*}{ Suppliers of Roses } & 1 & 4000 & 0.33 & 29 & 0.7 \\
\cline { 2 - 6 } & 2 & 3890 & 0.24 & 6 & 0.85 \\
\cline { 2 - 6 } & 3 & 4165 & 0.30 & 24 & 0.8 \\
\cline { 2 - 6 } & 4 & 3700 & 0.32 & 1 & 0.9 \\
\cline { 2 - 6 } & 5 & 3670 & 0.32 & 42 & 0.65 \\
\cline { 2 - 6 } & 8 & 4500 & 0.20 & 22 & 0.7 \\
\cline { 2 - 6 } & 9 & 3800 & 0.35 & 15 & 0.78 \\
\hline \multirow{3}{*}{ Suppliers of Gypso } & 12 & 2978 & 0.46 & 10 & 0.78 \\
\hline Suppliers of Calla & 13 & 2649 & 0.20 & 1 & 0.7 \\
\hline Suppliers of Hydrangea & 6 & 3025 & 0.19 & 1 & 0.75 \\
\hline Suppliers of Carnation & 7 & 3523 & 0.38 & 44 & 0.8 \\
\hline
\end{tabular}

The order management process starts when a non-fixed order arrives. FDLR does a product availability search among the various crop suppliers, and it takes into account the supplier's past performance and the number of negotiations it has had with it. When the search begins with the first supplier, its product availability is checked. If it has sufficient inventory, the order is placed and the customer is notified. If this supplier's inventory does not suffice, a consolidated amount with the available inventory of this crop is inputted, and the second supplier is evaluated. If it has sufficient inventory, the order is confirmed, otherwise the consolidated amount available is re-inputted along with the sum of the available crops evaluated. If this consolidated amount covers requirements, the order is confirmed; if not, the next crop supplier is evaluated. If after evaluating all the crop suppliers the consolidated amount does not cover the amount ordered by the customer, the customer is asked if it is willing to accept the consolidated amount available. If the customer does not accept these conditions, the order is withdrawn. If the customer accepts the consolidated amount available, the new order is confirmed. After confirming the new order, the delivery conditions are agreed on and this becomes a firm order to be passed to the order management subprocess, where products are ordered from crop suppliers through a purchasing order. Suppliers prepare the product in accordance with the purchasing order. If the product is served by a supplier in another city, the product is dispatched with no FDLR box and no quality inspection, which affects the image and quality of the product. These orders to a nonlocal crop supplier are placed because it is the only supplier that distributes a given type of product. No boxes are sent and no inspection is made because FDLR does not consolidate this product, but assigns this task to the transport company. While the crop supplier prepares the product, FDLR places an order of boxes with the cardboard factory. If the cardboard factory does not have enough inventory to serve FDLR's order, FDLR must invest more time in searching for another supplier to substitute the one that has failed. The cardboard factory prepares the boxes and delivers them to a transport company. This transport company can be the crop supplier(s)'s own or one that FDLP contracts. If the crop supplier is unable to collect boxes, FDLR must contract a transport company to transport the boxes to its crop supplier. 
When the boxes and product are available, the crop supplier prepares and places the product inside the boxes ready for quality inspection, after which boxes are loaded onto a refrigerated truck and are sent to the transport company.

\section{SIMULATION MODEL}

The firm commercialising flowers is a microenterprise with very limited economic and human resources. Nevertheless, this market has much potential. For this reason, this microenterprise wishes to make considerable progress to grow and become consolidated. Therefore, FDLR needs to set up strategies to help it meet its objective; increasing the firm's value by $300 \%$, by reflected in its equity, in a 1-year time horizon. This task may prove considerable given the investment it must make in general terms and with any of the more representative factors to achieve it. It must avoid investing in factors that do not offer increased profits and that make achieving its objective difficult at all costs. Therefore, the objective of simulation is to study the order management process in general by considering the different scenarios that originate from the proposals made by the firm.

In order to verify the model's performance, four scenarios apart from the initial one were designed, whose characteristics are presented in Table II. Later a fifth scenario was designed and created with the best results obtained in the simulation of the former scenarios. For these initial scenarios, a suppliers order is used in accordance with both the trust deposited and the past history of these firms.

Table II: Simulation scenarios.

\begin{tabular}{|l|c|c|c|c|c|c|}
\cline { 2 - 7 } \multicolumn{1}{c|}{} & $\begin{array}{c}\text { Initial } \\
\text { scenario }\end{array}$ & $\begin{array}{c}\text { Scenario } \\
\mathbf{1}\end{array}$ & $\begin{array}{c}\text { Scenario } \\
\mathbf{2}\end{array}$ & $\begin{array}{c}\text { Scenario } \\
\mathbf{3}\end{array}$ & $\begin{array}{c}\text { Scenario } \\
\mathbf{4}\end{array}$ & $\begin{array}{c}\text { Scenario } \\
\mathbf{5}\end{array}$ \\
\hline $\begin{array}{l}\text { Man hours/Attainment of } \\
\text { Customer }\end{array}$ & 1 & 6 & 1 & 1 & 1 & 1 \\
\hline Price Fixed Orders (\$) & 0.38 & 0.38 & 0.36 & 0.38 & 0.38 & 0.38 \\
\hline Price Non-Fixed Orders (\$) & 0.41 & 0.41 & 0.41 & 0.50 & 0.41 & 0.50 \\
\hline Marketing Investment & - & - & - & - & 10.00 & 10.00 \\
\hline Quality Staff & 1 & 1 & 1 & 1 & 1 & 2 \\
\hline
\end{tabular}

As from scenario 5, four additional scenarios are proposed by changing the supplier selection order according to the four criteria set out in Table III.

Table III: Supplier selection scenarios.

\begin{tabular}{|l|l|}
\hline Scenario 5-1 & Sort suppliers by availability \\
\hline Scenario 5-2 & Sort suppliers by price \\
\hline Scenario 5-3 & Sort suppliers by long-term payments \\
\hline Scenario 5-4 & Sort suppliers by higher product quality \\
\hline
\end{tabular}

To be able to construct the causal diagram, apart from modelling the chain structure, the work by [22] was taken into account. The target function of the model in this work was to maximise the firm's equity. With this mathematical model, the necessary treasury management model parts were extracted to help meet the objective of the present work, which is similar to that proposed in the publication by [22].

The proposed model is made up of various submodels that perform the following tasks. In relation to the order management model, the causal diagram created integrates, among others, variables to determine: the number of Current customers, the amount of orders by Fixed Orders and Non-fixed Orders, prices by Price of Fixed orders and Price of Non-fixed orders, the number of Flowers to purchase, Man Hours/Order Management, Accounts Receivable of 
FDLR, Income of FDLR and Payment deadline of FDLR, to determine Quality of Product (Quality Assurance, Quality of flowers, Quality Staff, etc.), Purchase Orders of boxes, Available stock of boxes and Outputs of boxes, Service level of the cardboard factory, Treasury Balance, Current Assets and the firm's Equity. Fig. 2 represents the connections among the factors of this model and its effects.

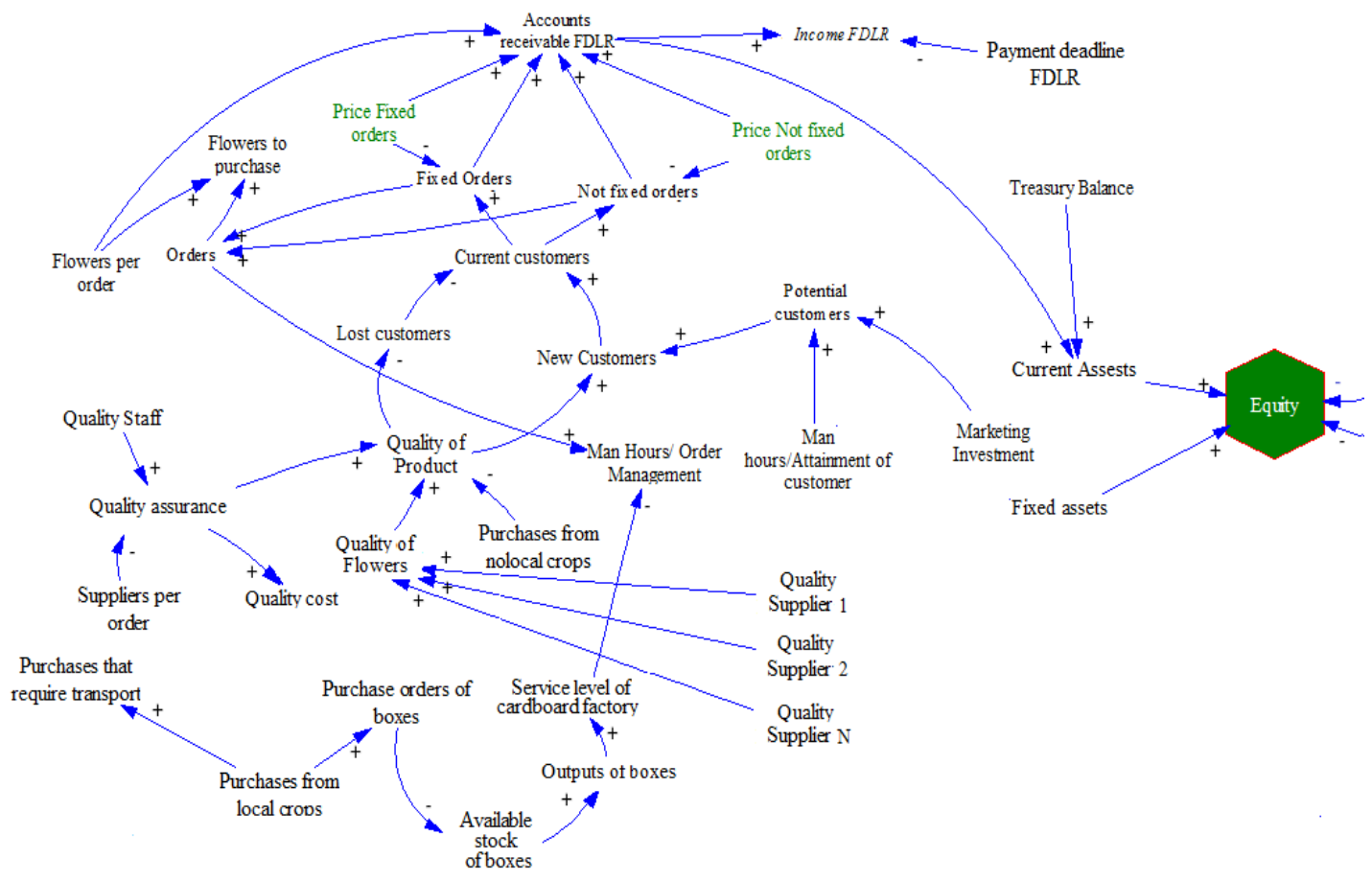

Figure 2: Causal loop diagram. Order management model.

The causal diagram of the suppliers' inventory management model integrates, among others, the variables to model the following processes: quantity of Stock of Suppliers 1, 2, etc., N, Supply from suppliers 1, 2, etc., N, Outputs of suppliers 1, 2, etc., N, Purchases from local crop suppliers, Purchases from non-local crop suppliers and Suppliers per order. Fig. 3 depicts the connections among the factors of this model and their effects.

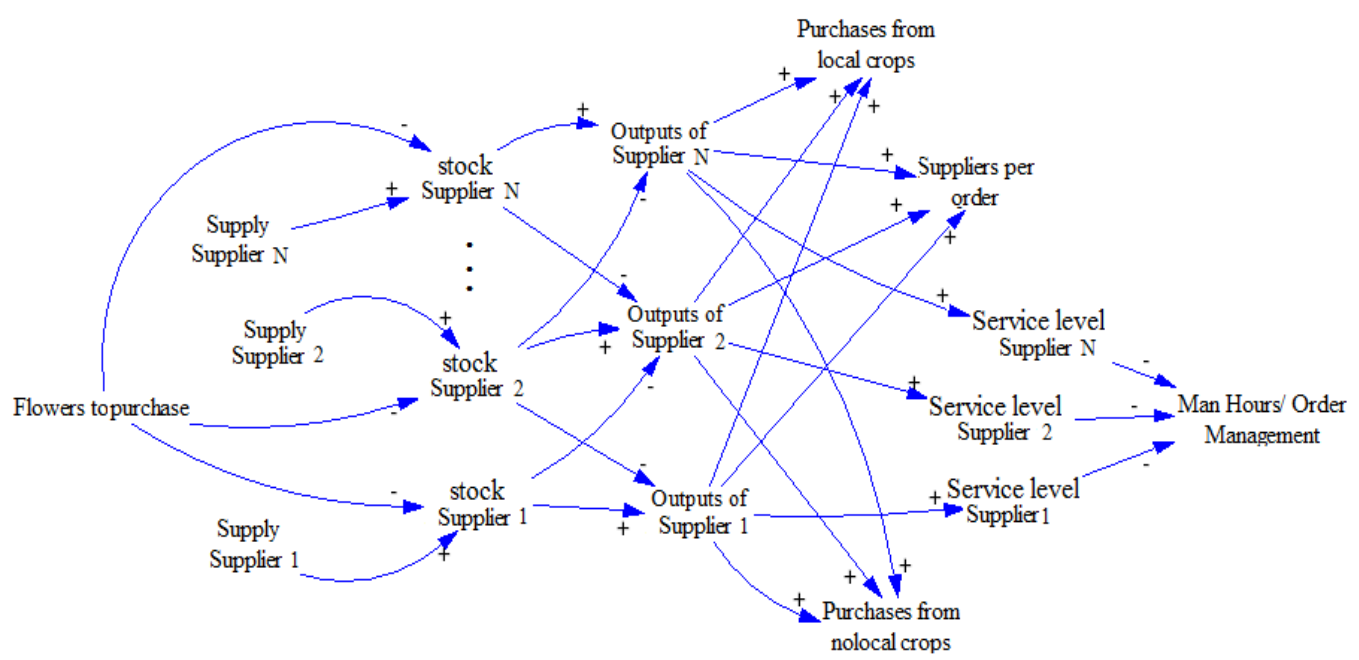

Figure 3: Causal loop diagram. Supplier inventory model.

The causal diagram of the model to manage costs and payments includes, among others, the variables for: Price of suppliers 1, 2, etc., N, Total costs of flowers, Flowers payments, 
Documentation costs (Costs of documentation opening and Shipping documentation costs), Total costs of boxes, Cardboard Factory's payment deadline, Labour costs, Labour Payments, Treasury Balance, Transport pays, State net credit (defined by Loan and Repayment), Line of credit, Monthly interest rate and Liabilities. Fig. 4 illustrates the connections among the factors of this model and their effects.

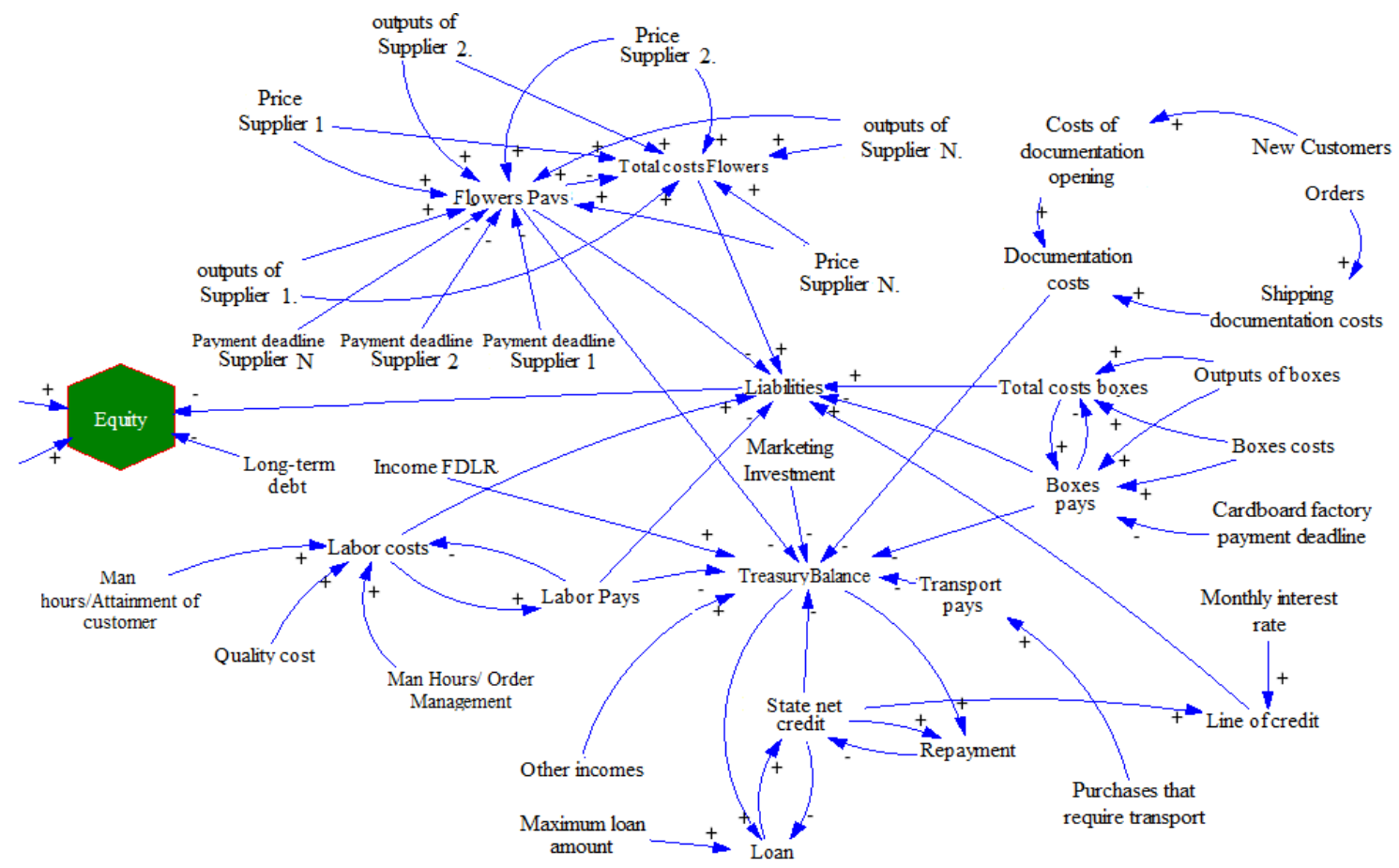

Figure 4: Causal diagram. Model of costs and payments.

Model validation is done by comparing the data obtained by the model with the data obtained in reality. The employed verification variables were Current customers, Flowers to purchase, Income of FDRL, Flowers Payments and Orders. With these data, the percentage of error was obtained, which is shown in Table IV.

Table IV: The model validation results.

\begin{tabular}{|l|c|c|c|c|c|}
\cline { 2 - 6 } \multicolumn{1}{c|}{} & $\begin{array}{c}\text { Current } \\
\text { customers } \\
\text { average }\end{array}$ & $\begin{array}{c}\text { Flowers to } \\
\text { purchase/year }\end{array}$ & $\begin{array}{c}\text { Income } \\
\text { FDLR/year }(\$)\end{array}$ & $\begin{array}{c}\text { Flower } \\
\text { pays/year }(\$)\end{array}$ & $\begin{array}{c}\text { Weekly } \\
\text { orders }\end{array}$ \\
\hline Model results & 10.59446721 & $247,559.62$ & $95,059.97$ & $78,061.34$ & 1.41 \\
\hline Real data of previous year & 11 & $254,797.00$ & $94,699.00$ & $78,774.00$ & 1.38 \\
\hline Percentage of difference & $\mathbf{3 . 7} \%$ & $\mathbf{2 . 8 \%}$ & $\mathbf{0 . 4 \%}$ & $\mathbf{0 . 9} \%$ & $\mathbf{2 . 0} \%$ \\
\hline
\end{tabular}

\section{EVALUATION OF THE RESULTS}

The simulation of the model was carried out with the Vensim ${ }^{\circledR}$ software. The initial set-up parameters were established as follows: Start Time: 0; End Time: 365; and Time Unit: days. Table V shows the input data, which varied for the evaluation of each scenario, as well as the results obtained in the most relevant variables.

How Equity performed among the first five scenarios, in comparison to the simulation of the initial scenario, is seen in Fig. 5. Despite Equity representing a positive status in the initial simulation when the simulation period ended, it lowered from approximately period 60. This descent was shown by the Treasury balance, which was affected by many factors. However, the situation that seemed to have an effect was the combination between Income of FDLR and 
Labour Payments as Labour Payments were higher than income. Although income was constant and payments were periodical, these payments affected the Treasury balance during these periods as they hindered income from recovering this balance. This implies that income is not high enough to properly use of economies of scale to cover payments.

Table V: Scenarios. Results.

\begin{tabular}{|c|c|c|c|c|c|c|c|c|c|c|c|c|c|}
\hline \multicolumn{4}{|c|}{ Input Data } & 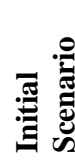 & 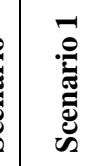 & 華 & 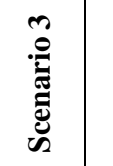 & 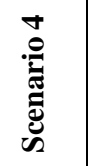 & م & 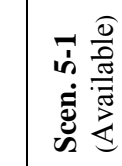 & 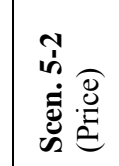 & 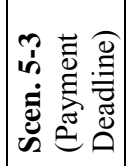 & 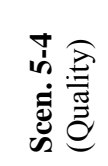 \\
\hline \multicolumn{4}{|c|}{ Man hours/Attain. customer } & 1 & 6 & 1 & 1 & 1 & 6 & 6 & 6 & 6 & 6 \\
\hline \multicolumn{4}{|c|}{ Prices F of Fixed (\$) } & 0.38 & 0.38 & 0.36 & 0.38 & 0.38 & 0.3 & 0.38 & 0.38 & 0.38 & 0.38 \\
\hline \multicolumn{4}{|c|}{ Prices $\mathbf{F}$ of non-Fixed $(\$)$} & 0.41 & 0.41 & 0.41 & 0.50 & 0.41 & 0.5 & 0.50 & 0.50 & 0.50 & 0.50 \\
\hline \multicolumn{4}{|c|}{ Marketing Investment (\$) } & - & - & - & - & 10.00 & 10.0 & 10.00 & 10.00 & 10.00 & 10.00 \\
\hline \multicolumn{4}{|c|}{ Quality Staff } & 1 & 1 & 1 & 1 & 1 & 2 & 2 & 2 & 2 & 2 \\
\hline \multirow{12}{*}{ 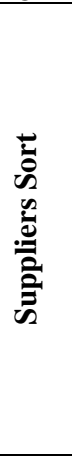 } & \multirow{8}{*}{ Roses } & \multicolumn{2}{|c|}{ Priority 1} & 3 & 3 & 3 & 3 & 3 & 3 & 8 & 5 & 5 & 4 \\
\hline & & \multicolumn{2}{|c|}{ Priority 2} & 8 & 8 & 8 & 8 & 8 & 8 & 3 & 8 & 1 & 2 \\
\hline & & \multicolumn{2}{|c|}{ Priority 3} & 4 & 4 & 4 & 4 & 4 & 4 & 1 & 1 & 3 & 3 \\
\hline & & \multicolumn{2}{|c|}{ Priority 4} & 5 & 5 & 5 & 5 & 5 & 5 & 2 & 2 & 8 & 9 \\
\hline & & \multicolumn{2}{|c|}{ Priority 5} & 1 & 1 & 1 & 1 & 1 & 1 & 9 & 12 & 9 & 12 \\
\hline & & \multicolumn{2}{|c|}{ Priority 6} & 2 & 2 & 2 & 2 & 2 & 2 & 4 & 3 & 12 & 1 \\
\hline & & \multicolumn{2}{|c|}{ Priority 7} & 9 & 9 & 9 & 9 & 9 & 9 & 5 & 9 & 2 & 8 \\
\hline & & \multicolumn{2}{|c|}{ Priority 8} & 12 & 12 & 12 & 12 & 12 & 12 & 12 & 4 & 4 & 5 \\
\hline & \multirow{2}{*}{ Gypso } & \multicolumn{2}{|c|}{ Priority 1} & 11 & 11 & 11 & 11 & 11 & 11 & 13 & 13 & 13 & 13 \\
\hline & & \multicolumn{2}{|c|}{ Priority 2} & 13 & 13 & 13 & 13 & 13 & 13 & 11 & 11 & 11 & 11 \\
\hline & \multirow{2}{*}{ Calla } & \multicolumn{2}{|c|}{ Priority 1} & 6 & 6 & 6 & 6 & 6 & 6 & 6 & 10 & 6 & 6 \\
\hline & & \multicolumn{2}{|c|}{ Priority 2} & 10 & 10 & 10 & 10 & 10 & 10 & 10 & 6 & 10 & 10 \\
\hline \multicolumn{14}{|c|}{ RESULTS } \\
\hline \multicolumn{2}{|c|}{ Equity (\$) } & 4,380 & \multicolumn{2}{|c|}{6,959} & 1,600 & 11,394 & 5,200 & 18,0 & & 34,169 & 34,126 & 31,204 & $(16,362)$ \\
\hline Cur & $\operatorname{ssets}(\$)$ & 212 & & & 197 & 6,401 & 331 & 14,0 & & 28,947 & 29,147 & 26,231 & 1,197 \\
\hline Fixe & ets $(\$)$ & 10,000 & & 000 & 10,000 & 10,000 & 10,000 & 10,0 & & 10,000 & 10,000 & 10,000 & 10,000 \\
\hline Liab & S (\$) & 832 & & & 3,596 & 7 & 131 & 1,0 & & $(222)$ & 22 & 27 & 22,559 \\
\hline Lon & $\mathrm{n}$ Debt $(\$)$ & 5,000 & & & 5,000 & 5,000 & 5,000 & 5,00 & & 5,000 & 5,000 & 5,000 & 5,000 \\
\hline Tres & balance $(\$)$ & $(61)$ & & & (64) & 6,123 & $(144)$ & 12,9 & & 28,045 & 28,741 & 25,808 & (499) \\
\hline Line & redit (\$) & 860 & & & 3,639 & - & - & - & & - & - & - & 21,058 \\
\hline Loa & & 61 & & & 64 & - & 144 & - & & - & - & - & 499 \\
\hline Inco & $\operatorname{DLR}(\$)^{*}$ & 95,060 & & 299 & 93,264 & 95,049 & 146,892 & 270, & 439 & 219,327 & 122,056 & 126,089 & 365,550 \\
\hline $\mathrm{Lab}$ & ays $(\$)^{*}$ & 9,029 & & & 9,088 & 8,580 & 14,585 & 29,7 & & 24,191 & 15,263 & 15,716 & 42,607 \\
\hline Flov & ays $(\$)^{*}$ & 78,061 & & 513 & 78,750 & 72,119 & 113,814 & 197, & 156 & 142,270 & 61,332 & 67,912 & 303,274 \\
\hline $\begin{array}{l}\text { Mar } \\
\text { Mar }\end{array}$ & $\begin{array}{l}\text { rs/Order } \\
\text { hent** }\end{array}$ & 6 & & & 6 & 5 & 10 & 19 & & 14 & 8 & 8 & 30 \\
\hline Wee & Prders** & 140 & & & 1.42 & 1.30 & 2.18 & 3.7 & & 3.00 & 1.67 & 1.73 & 5.10 \\
\hline $\mathrm{Cus}$ & r** & 10.60 & & & 10.20 & 11.70 & 16.42 & 33. & & 27.30 & 15.00 & 15.60 & 45.70 \\
\hline
\end{tabular}

Note: The values are those resulting during the last period simulated except $(*)$ and $(* *)$.

$(*)$ : Accumulated values throughout the simulation horizon. $(* *)$ : Average values of the entire simulation horizon.

In the simulation of Scenario 1, where the objective was to increase the customer portfolio to boost the firm's income, the average number of customers a year increased by almost $80 \%$, which means that Man hours/Attainment of customers also rose. The comparison made between this scenario with the initial one provided a better result in Equity, which rose by approximately $36 \%$. However, no increase was constant, but remained stable as from period 60 .

Scenario 2 seeks to increase orders by lowering the purchasing price for fixed orders. Despite reducing the variable Price Fixed orders, it did not considerably encourage more orders, but actually lowered the firm's income. Therefore, the performance of the firm's Equity diminished substantially. In this scenario, Assets did not compensate Liabilities, and by the time half the period was simulated, the credit line rose, which means an even greater increase in Liabilities. 
Scenario 3 intends to raise income by increasing the prices for non-fixed orders; that is, Price Non-Fixed orders. This scenario increased the Equity value by $160 \%$ at the end of the simulated period, but the numbers obtained for income and customers were similar to what they were before. This increase obtained in Equity by maintaining similar income levels basically came about through the smaller number of weekly orders which, despite not being apparently significant, had an impact on the costs and payments factors, which helped the Treasury balance to significantly increase. Levels of income were similar to those in the initial scenario and in Scenario 2, but slight increases during some periods were noted. Furthermore at the end of the simulation period, various costs slightly lowered if compared to the other scenarios. These slight increases in income, along with minor reductions in the various costs or payments presented in the simulation of this scenario, helped not only increase the Treasury balance, but also significantly increase Equity.

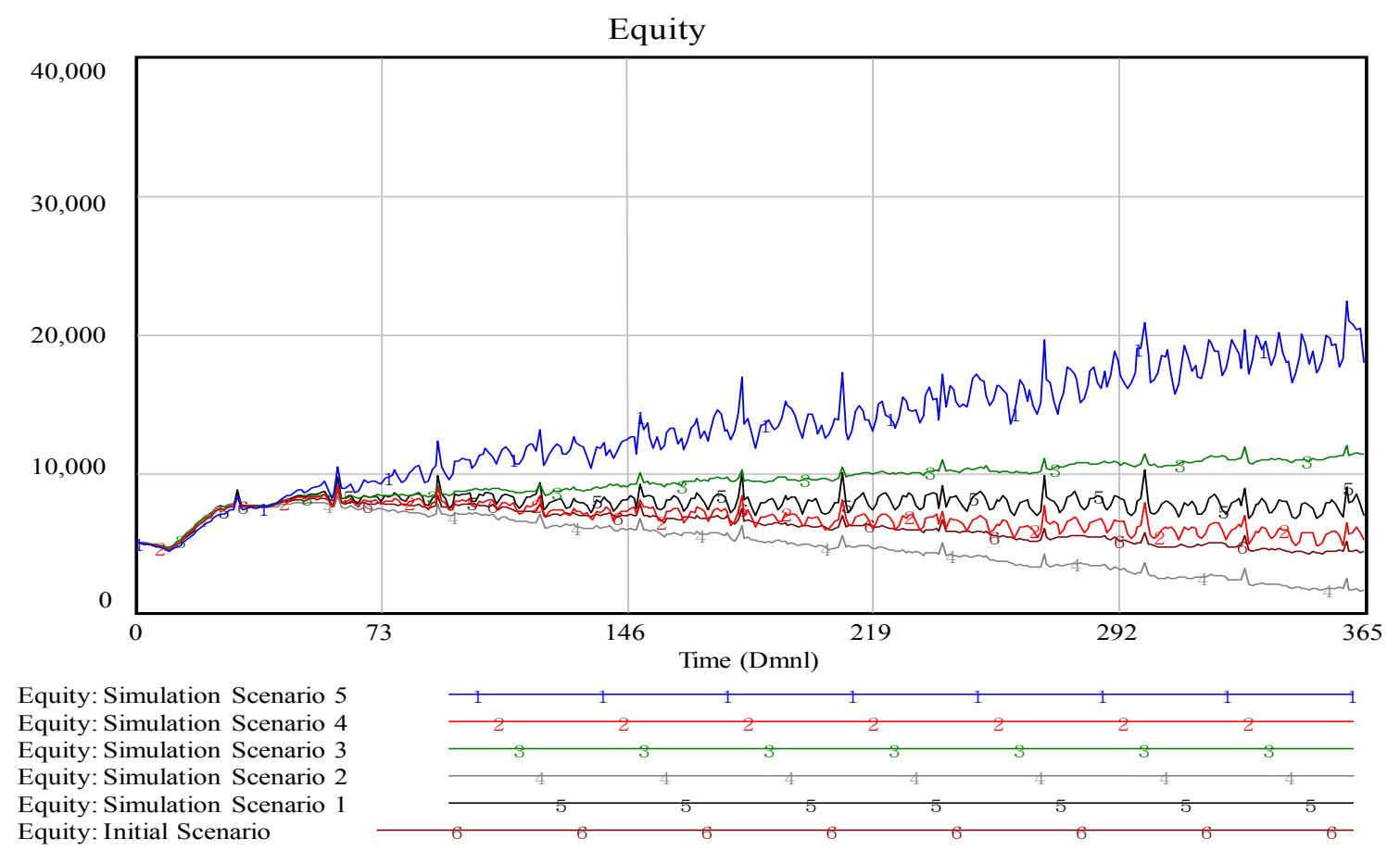

Figure 5: Equity in the simulation of scenario 5.

Scenario 4 offers a slight increase of around $19 \%$ for the evaluation objective, which was far from meeting the objective, and even tended to lower. It exhibited similar performance to that presented in Scenario 1 as it enabled the Current customers portfolio to increase. However, obtained income did not cover the payments made as the periods elapsed.

The simulation of Scenario 5 intends to collect the data amended in previous scenarios, which generated a positive result or a better one than the current Equity status. To simulate this scenario, in this order the data considered in Scenarios 1, 3 and 4 were amended. Finally, contracting extra personnel was considered to ensure quality and, accordingly, to avoid Lost customers and Marketing investment or in Man hours/Attainment of customers. In this scenario, the results improved substantially and the objective was met given the $310 \%$ increase in Equity. In this case, income made good use of economies of scale to face different payments, as reflected by the Treasury balance levels. In general, this scenario considered growth for all aspects by putting economies of scale to better use, which enabled the value acquired by the firm to constantly grow. Next the performance of Equity among the four previous scenarios (Scenario 5-1, Scenario 5-2, Scenario 5-3 and Scenario 5-4) is presented, and was compared with the simulation of Scenario 5 (see Fig. 6). 
Scenario 5-1 of the flowers supplier selection, as of Scenario 5, provided an order of priority according to each supplier's product availability; in other words, the supplier that could offer a larger quantity of weekly produce to the firm. This scenario shows a sharp rise in Equity if compared with the initial scenario and Scenario 5, with increases of $680 \%$ and $90 \%$, respectively. This was due to an increase in the firm's Assets, but its Liabilities remained at similar levels, or at lower ones than in Scenario 5. Nonetheless, this scenario provided fewer generated orders because Quality of Product diminished due to the selected suppliers not relying on better quality. Despite the reduction in generated orders, which was not significant, the Man hours/Order Management reduced as the suppliers' service level became higher; thus, the time that must be invested in seeking more products was cut.

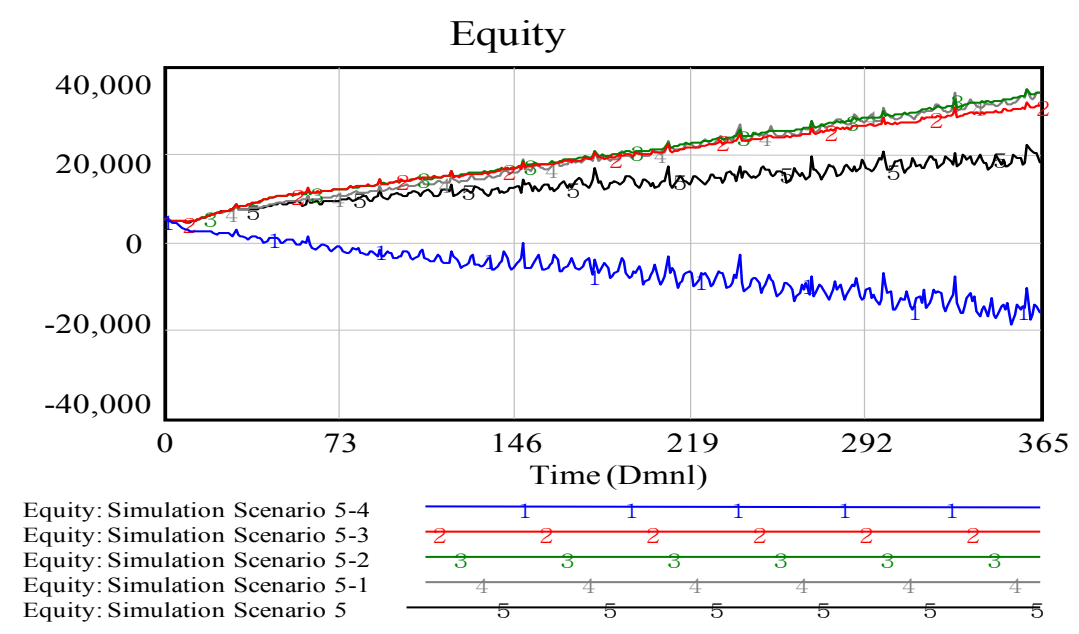

Figure 6: Equity simulation of scenario 5-4.

If we were to begin with the simulation of Scenario 5 for Scenario 5-2, an order of priority would be given to suppliers according to the price per flower offered to the firm. In this scenario, we also noted a significant increase in Equity if compared to Scenario 5, which was slightly lower than in Scenario 5-1. Yet this scenario had a smaller number of generated orders. The difference was that, despite receiving fewer orders than in former scenarios, Flowers Payments lowered. In this case, based on the order of priority in supplier selection, orders were generated according to price; product availability was affected because top priority was given to a supplier with worse product availability than other suppliers.

In Scenario 5-3, the order was determined according to the longer payment deadlines that the suppliers offered. In this case, the reaction to the model was interesting because, despite giving priority to the suppliers offering longer payment deadlines, 3 of the 4 first ones in this priority order actually presented poorer product quality. For this reason, Equity during the first half of the simulated period increased more than in the other scenarios thanks to lengthy payment deadlines. However during the second half of the period, Equity started to drop slightly below the levels of scenario 5-1 owing to slight, yet accumulated, customer losses since Quality of Product maintained Liabilities at high levels. This gave rise to an abrupt rise in Lost customers, orders and income at the end of the period. Scenarios 5-2 and 5-3 performed similarly. However, Scenario 5-2 provided better Equity because it had fewer Liabilities thanks to products being acquiring at better prices.

If we were to begin with Scenario 5, Scenario 5-4 would be created by ordering the suppliers according to product quality. This scenario's performance was even more interesting than the previous ones as it provided the worst result despite generating the largest number of customers, orders and income. Not only did it generate the worst Equity of all ten scenarios, but it presented a negative value. This situation can be explained by the fact that suppliers' priority was established according to Quality of Product and product delivered, and the 
number of orders was much higher than in the other scenarios. Nevertheless, the two first suppliers in the priority order according to quality offered the shortest payment deadlines, and their available inventory levels were among the lowest. If we were to bear this in mind, as the firm allowed a 10-day payment deadline to its customers, it would not immediately count on the balance to pay its suppliers. So it had to constantly apply for loans to cover payments, which were increased by personnel costs after increasing the time that the firm had to invest because these suppliers had no available inventory, which is detrimental to service levels.

In short, both the simulation objective and the firm's objective were accomplished by modelling a supply chain and by reaching an Equity value of $\$ 34,169$. If were to consider that the current Equity value was $\$ 4,380$, and that the objective of the model was to increase Equity by $300 \%$, we could state that the objective was met thanks to the $680 \%$ increase in the Equity value.

The decisions to be made by the firm to meet its year-end objective should be those established in Scenario 5-1. This implies the following: increasing the amount of man hours by 9 hours per day to exclusively attain potential customers; putting up the sale price of its products for non-fixed or regular orders by a value of $\$ 0.50$ per flower; adopting a policy of investing \$10 per day in marketing to attain more customers; contracting the services of another person for the Quality of Product inspection; and giving priority to purchasing from those suppliers with a better available inventory of flowers.

\section{CONCLUSIONS}

The present work has modelled almost all the factors that affect the order management process of a flower-exporting supply chain, and has left those factors that are difficult to model to one side. Nonetheless, since the central organisation of the supply chain is a microenterprise, called FDLR, we can state that all the factors which influence it do so to a great extent because, given its size, it is more difficult for FDLR to react or to allocate resources to mitigate any effect. Neither flows nor material inventories have been included because it is assumed that FDLR manages an assembly to adopt the strategy where assembly is done thanks to FDLR's management. However, it never comes into physical contact with raw materials, packaging or the end product. For this very special case, the only factors which guarantee the order being fulfilled are quality inspection and the transport company's confirmation that the order has been sent. The considered scenarios contain factors that are easy for the firm to amend and they represent options that have been previously proposed within the firm. The main factors that affect the financial evaluation contemplated by [22] have been successfully identified and applied, which enables a more direct estimation of the firm's value. If what the authors considered is not applied, the obtained result will differ when evaluating other factors that do not reliably represent the firm's value. Modelling has enabled us to discover that not only the lowest price and quality are the most relevant factors for supplier selection.

The majority of the literature on the aspects reviewed in this work consider the use of the $\mathrm{ABC}$ approach the main method to truly identify the costs associated with the activities included in a process, and reveal that it is increasingly important to know the true costs associated with a product. Order management modelling that focuses on cutting costs or on improving profits by considering the cost/profit ratio to reject or accept an order is of widespread use. In general, decision making for the supplier selection problem relies on many evaluation criteria such as price, quality, delivery, geographic location, etc. A good number of works contemplate the use of fuzzy linear programming to deal with the supplier selection problem. For financial evaluations, models which integrate production planning problems or effects of operations and cash flow or financial effects are used. 
While this work was underway, several future research lines were identified: (1) integrating other aspects or factors that may not have been detected to model the supply chain's operation; (2) integrating new supplier selection criteria, such as geographic location or distance, financial position, placement in industry, attitude, etc., which can be easily detected for this case; (3) contemplating a more exhaustive evaluation of the supplier selection criteria which are given priority by not only one criterion, but also by a combination of criteria. In this way, it may be possible to make full use of suppliers with good quality levels for their products which, at the same time, have sufficient inventory available to offer acceptable service levels; (4) extending the supplier selection consideration at the cardboard factory level to increase the firm's sales where more than one supplier of this product type is required. New trends have appeared in the literature [25-29], such as sustainability, green production planning, or production planning with carbon emissions; (5) considering the model with the ABC approach to obtain a better product cost by separating the manpower, transport and documentation costs, etc., for each product offered. In this way, the firm's costs can be better controlled.

\section{ACKNOWLEDGEMENT}

This paper has been funded by the Spanish Ministry Project entitled Design and Management of Global Supply Chains (GLOBOP) (Ref. DPI2012-38061-C02-01).

\section{REFERENCES}

[1] Cooper, M. C.; Lambert, D. M.; Pagh, J. D. (1997). Supply chain management: more than a new name for logistics, The International Journal of Logistics Management, Vol. 8, No. 1, 1-14, doi: $10.1108 / 09574099710805556$

[2] Campuzano, F.; Mula, J. (2011). Supply Chain Simulation: A System Dynamics Approach for Improving Performance, Springer-Verlag, London

[3] Calderon, J. L.; Lario, F. C. (2007). Simulación de cadenas de suministro: Nuevas aplicaciones y áreas de desarrollo, Información Tecnológica, Vol. 18, No. 1, 137-146, doi:10.4067/S071807642007000100018

[4] Terzi, S.; Cavalieri, S. (2004). Simulation in the supply chain context: a survey, Computers in Industry, Vol. 53, No. 1, 3-16, doi:10.1016/S0166-3615(03)00104-0

[5] Buchmeister, B.; Friscic, D.; Palcic, I. (2013). Impact of demand changes and supply chain's level constraints on bullwhip effect, Advances in Production Engineering \& Management, Vol. 8, No. 4, 199-208, doi:10.14743/apem2013.4.167

[6] Sterman, J. D. (2000). Business Dynamics: Systems Thinking and Modeling for a Complex World, Irwin-McGraw Hill, Boston

[7] Forrester, J. (1961). Industrial Dynamics, M.I.T. Press, Cambridge

[8] Alarcón, F.; Verdecho, M. J.; Alemany, M. M. E.; Lario, F. C. (2009). A conceptual framework for modelling the collaborative order management process, International Conference on Interoperability for Enterprise Software and Applications China, 70-75

[9] Abid, C.; D'amours, S.; Montreuil, B. (2004). Collaborative order management in distributed manufacturing, International Journal of Production Research, Vol. 42, No. 2, 283-302, doi: $10.1080 / 00207540310001602919$

[10] Jung, H.; Jeong, B.; Lee, C.-G. (2008). An order quantity negotiation model for distributor-driven supply chains, International Journal of Production Economics, Vol. 111, No. 1, 147-158, doi:10.1016/j.ijpe.2006.12.054

[11] Khataie, A.; Defersha, F. M.; Bulgak, A. A. (2010). A multi-objective optimisation approach for order management: incorporating activity-based costing in supply chains, International Journal of Production Research, Vol. 48, No. 17, 5007-5020, doi:10.1080/00207540903095442

[12] Khataie, A. H.; Bulgak, A. A.; Segovia, J. J. (2011). Activity-based costing and management applied in a hybrid decision support system for order management, Decision Support Systems, Vol. 52, No. 1, 142-156, doi:10.1016/j.dss.2011.06.003 
[13] Kirche, E. T.; Kadipasaoglu, S. N.; Khumawala, B. M. (2005). Maximizing supply chain profits with effective order management: integration of activity-based costing and theory of constraints with mixed-integer modelling, International Journal of Production Research, Vol. 43, No. 7, 1297-1311, doi: $10.1080 / 00207540412331299648$

[14] Kirche, E.; Srivastava, R. (2005). An ABC-based cost model with inventory and order level costs: a comparison with TOC, International Journal of Production Research, Vol. 43, No. 8, 1685-1710, doi: $10.1080 / 002075412331317836$

[15] Wang, Q.; Liu, S.; Gao, B.; Wang, D. (2011). An optimization model for the order dispatching problem in distributed production environment, 2011 Chinese Control and Decision Conference (CCDC), 1444-1449, doi:10.1109/CCDC.2011.5968419

[16] Dordevic, M. S.; Zrnic, N. D.; Milicevic, M. R.; Miskovic, V. V. (2013). Information and material flow modeling in system of parts regeneration in multi-level supply system, Technical Gazette, Vol. 20, No. 5, 861-869

[17] Amin, S. H.; Razmi, J.; Zhang, G. (2011). Supplier selection and order allocation based on fuzzy SWOT analysis and fuzzy linear programming, Expert Systems with Applications, Vol. 38, No. 1, 334-342, doi:10.1016/j.eswa.2010.06.071

[18] Ding, H.; Benyoucef, L.; Xie, X. (2005). A simulation optimization methodology for supplier selection problem, International Journal of Computer Integrated Manufacturing, Vol. 18, No. 23, 210-224, doi:10.1080/0951192052000288161

[19] Lin, R.-H. (2009). An integrated FANP-MOLP for supplier evaluation and order allocation, Applied Mathematical Modelling, Vol. 33, No. 6, 2730-2736, doi:10.1016/j.apm.2008.08.021

[20] Mafakheri, F.; Breton, M.; Ghoniem, A. (2011). Supplier selection-order allocation: A two-stage multiple criteria dynamic programming approach, International Journal of Production Economics, Vol. 132, No. 1, 52-57, doi:10.1016/j.ijpe.2011.03.005

[21] Zouggari, A.; Benyoucef, L. (2012). Simulation based fuzzy TOPSIS approach for group multicriteria supplier selection problem, Engineering Applications of Artificial Intelligence, Vol. 25, No. 3, 507-519, doi:10.1016/j.engappai.2011.10.012

[22] Comelli, M.; Fenies, P.; Tchernev, N. (2008). A combined financial and physical flows evaluation for logistic process and tactical production planning: Application in a company supply chain, International Journal of Production Economics, Vol. 112, No. 1, 77-95, doi:10.1016/ j.ijpe.2007.01.012

[23] Smith, N. R.; Martinez-Flores, J. L. (2007). Discrepancies in solutions between traditional and net present value formulations of finite horizon, discrete-time economic lot size problems, International Journal of Production Research, Vol. 45, No. 24, 5731-5741, doi:10.1080/ $\underline{00207540600891416}$

[24] Guillen, G.; Badell, M.; Espuña, A.; Puigjaner, L. (2006). Simultaneous optimization of process operations and financial decisions to enhance the integrated planning/scheduling of chemical supply chains, Computers \& Chemical Engineering, Vol. 30, 421-436, doi:10.1016/j. compchemeng.2005.10.015

[25] Guillen, G.; Badell, M.; Puigjaner, L. (2007). A holistic framework for short-term supply chain management integrating production and corporate financial planning, International Journal of Production Economics, Vol. 106, No. 1, 288-306, doi:10.1016/j.ijpe.2006.06.008

[26] Gurning, S.; Cahoon, S.; Dragovic, B.; Nguyen, H. O. (2013). Modelling of multi-mitigation strategies for maritime disruptions in the wheat supply chain, Strojniski vestnik - Journal of Mechanical Engineering, Vol. 59, No. 9, 499-510, doi:10.5545/sv-jme.2012.941

[27] Vlachos, D.; Georgiadis, P.; Iakovou, E. (2007). A system dynamics model for dynamic capacity planning of remanufacturing in closed-loop supply chains, Computers \& Operations Research, Vol. 34, No. 2, 367-394, doi:10.1016/j.cor.2005.03.005

[28] Srivastava, S. K. (2008). Network design for reverse logistics, Omega, Vol. 36, No. 4, 535-548, doi:10.1016/j.omega.2006.11.012

[29] Mangla, S.; Madaan, J.; Chan, F. T. S. (2013). Analysis of flexible decision strategies for sustainability-focused green product recovery system, International Journal of Production Research, Vol. 51, No. 11, 3428-3442, doi:10.1080/00207543.2013.774493 